\title{
Reactivity of Alcohols in Chemoselective Transfer Hydrogenation of Acrolein over Magnesium Oxide as the Catalyst
}

\author{
Marek Gliński • Urszula Ulkowska
}

Received: 13 April 2010/Accepted: 3 November 2010/Published online: 20 November 2010

(C) The Author(s) 2010. This article is published with open access at Springerlink.com

\begin{abstract}
This paper presents the first full thermodynamic description of the hydrogen transfer between acrolein, the simplest $\alpha, \beta$-unsaturated aldehyde, and a set of aliphatic alcohols, both primary and secondary. The vapour phase transfer hydrogenation of acrolein into allyl alcohol with various primary and secondary aliphatic alcohols used as hydrogen donors in the presence of $\mathrm{MgO}$ as the catalyst has been studied. Despite differentiated reactivity exhibited by these alcohols, a high chemoselectivity $(>80 \%)$ to allyl alcohol has been observed for all of them. On the basis of thermodynamic calculations it has been found that secondary alcohols as hydrogen donors are more reactive than primary ones. However, ethanol or butan-1-ol have shown the highest reactivity. In their presence yields of allyl alcohol higher than $60 \%$ have been noted, which greatly exceed those predicted by thermodynamic calculations based on the following equation: acrolein + ethanol (butan-1-ol) $\rightarrow$ allyl alcohol + acetaldehyde (butyraldehyde). Although similar yields have been reported in literature, no subsequent nor side reactions have been discussed even though the attained yield cannot be accounted for by this reaction alone. As a possible explanation of the discrepancy the occurrence of a disregarded reaction, for which $\Delta G<0$, has been considered. It has been shown that aldol condensation fulfills these thermodynamic requirements, however, the products of this reaction are noted only at the beginning of the process and the decrease of their amount does not influence the yield of allyl alcohol.
\end{abstract}

M. Gliński ( $\square)$ · U. Ulkowska

Department of Catalysis and Organometallic Chemistry, Faculty of Chemistry, Warsaw University of Technology (Politechnika), Noakowskiego 3, 00-664 Warsaw, Poland

e-mail: marekg@ch.pw.edu.pl
Keywords Acrolein - Allyl alcohol · Hydrogen transfer . Magnesia - Chemoselectivity · Thermodynamics

\section{Introduction}

Unsaturated alcohols are very important and versatile intermediates for pharmaceutical, polymer, fragrance, and food industries. The main route for their synthesis is the selective hydrogenation of $\alpha, \beta$-unsaturated carbonyl compounds. Conventional reduction of these compounds by gaseous dihydrogen over many metal catalysts results in preferable hydrogenation of the $\mathrm{C}=\mathrm{C}$ bond [1-5]. Recently, metallic gold dispersed on $\mathrm{FeOOH}$ or $\gamma-\mathrm{Fe}_{2} \mathrm{O}_{3}$ has shown a remarkable chemoselectivity in the reduction of the conjugated $\mathrm{C}=\mathrm{O}$ bond in the $\alpha, \beta$-unsaturated carbonyl compounds $[6,7]$.

Catalytic transfer hydrogenation $(\mathrm{CTH})$ has been found to be an efficient and selective method to synthesize unsaturated alcohols [8-10]. Metal oxides, $\operatorname{MgO}[11,12]$, $\mathrm{ZrO}_{2}$ [13], double layered hydroxides [14], $\mathrm{MgO}-\mathrm{B}_{2} \mathrm{O}_{3}$ [15], and $\mathrm{Al}_{2} \mathrm{O}_{3}-\mathrm{AlPO}_{4}$ [16] have been used as catalysts. According to literature data, $\mathrm{MgO}$ is one of the most active catalysts in CTH $[17,18]$.

Acrolein, the simplest $\alpha, \beta$-unsaturated aldehyde, is considered one of the most difficult compounds to be reduced to the unsaturated alcohol [19]. The first study on $\mathrm{CTH}$ of acrolein and other $\alpha, \beta$-unsaturated carbonyl compounds was performed more than 50 years ago [20]. Oxides of magnesium, calcium, aluminum, zinc and cadmium, and a mixture of $\mathrm{MgO}-\mathrm{ZnO}$ have been used as catalysts. It has been shown that the catalysts which contain $\mathrm{MgO}$ were the most active and chemoselective towards allyl alcohol. Moreover, a differentiated reactivity of primary and secondary alcohols as hydrogen donors to acrolein has been 
found. Very little is known about the reasons of their reactivities besides the fact that they are weakly influenced by the structure of substituents surrounding the carbinol carbon atom. A higher reactivity of ethanol towards acrolein than propan-2-ol has been noted [20]. Moreover, in the CTH of $\alpha, \beta$-unsaturated aldehydes other than acrolein, a much higher reactivity of propan-2-ol compared to that of ethanol has been observed [15, 21].

In this work a systematic study of the reactivity of various aliphatic alcohols as hydrogen donors to acrolein in its vapour-phase transfer hydrogenation over pure magnesium oxide as the catalyst has been performed. A description of low and high reactivities of alcohols has been given and the obtained values have been compared with those resulted from the thermodynamic calculations. Very high reactivity of ethanol as the hydrogen donor to acrolein observed for $\mathrm{MgO}$ [20, 22], significantly exceeding that of propan-2-ol [21], has been confirmed by us. Moreover, we have also found that butan-1-ol is a very reactive hydrogen donor and the observed reactivities of ethanol and butan-1-ol are higher than those predicted by the thermodynamic calculations based on the following equation: acrolein + ethanol (butan-1-ol) $\rightarrow$ allyl alcohol + acetaldehyde (butyraldehyde). This discrepancy has not yet been accounted for.

\section{Experimental}

Catalyst. To a suspension of $180 \mathrm{~g}$ of $\mathrm{MgO}$ (purum p.a., Reachim) in $2 \mathrm{dm}^{3}$ of redistilled water nitric acid (68\%, p.a., POCh Gliwice, Poland) was slowly added with stirring (c.a. $540 \mathrm{~cm}^{3}$ ). After cooling a slightly turbid solution was filtered and purified by partial precipitation of $\mathrm{Mg}(\mathrm{OH})_{2}$ using $130 \mathrm{~cm}^{3}$ of ammonia solution (25\%, p.a., POCh Gliwice, Poland). The resulted suspension was stirred for $72 \mathrm{~h}$ at room temperature and filtered off. To this clear solution an excess of $25 \%$ ammonia solution $\left(1.2 \mathrm{dm}^{3}\right)$ was slowly added with stirring. The precipitate of $\mathrm{Mg}(\mathrm{OH})_{2}$ was washed by decantation with redistilled water ( 25 times, $1 \mathrm{dm}^{3}$ in each washing) and dried under normal pressure at 313, 353 and $393 \mathrm{~K}$ for $24 \mathrm{~h}$ at each temperature. The dried powder of purified $\mathrm{Mg}(\mathrm{OH})_{2}$ (165 g) was pelletized and the pellets were crushed. A sieved fraction of $0.16-0.40 \mathrm{~mm}$ was calcined in a tubular quartz reactor at $873 \mathrm{~K}$ for $1 \mathrm{~h}$ in a stream of air and for $5 \mathrm{~h}$ in a stream of dry deoxygenated nitrogen. After cooling in a stream of nitrogen, $\mathrm{MgO}$ was transferred to a Schlenk-type container and stored under nitrogen. The same batch of $\mathrm{Mg}(\mathrm{OH})_{2}$ has been used by us before [23].

Magnesium oxide and its precursor- $\mathrm{Mg}(\mathrm{OH})_{2}$, were characterized by a number of techniques, such as: XRD, nitrogen physisorption, TG-DTA, as well as the Hammett method for determining acidic-basic properties of surfaces. The precursor was heated to $473 \mathrm{~K}$ for $6 \mathrm{~h}$ in a stream of dry nitrogen before all measurements. Powder diffraction data were collected on a D-5000 diffractometer (Siemens) equipped with a scintillation counter and Ni-filtered $\mathrm{Cu} \mathrm{K}_{\alpha}$ radiation. The surface areas of the samples were measured using a Micromeritics ASAP 2020 instrument. The TG-DTA measurements were performed using a NETZSCH STA 449C thermobalance. The samples were heated up to $873 \mathrm{~K}$ in Ar flow $\left(10 \mathrm{~cm}^{3} \mathrm{~min}^{-1}\right.$, heating ramp $10 \mathrm{deg} \min ^{-1}$ ). The data was processed with NETZSCH Proteus Thermal Analysis software. The strength of the surface acid-base sites of $\mathrm{MgO}$ was determined by the Hammett method using a sequence of indicators in anhydrous toluene as the solvent [24]. The concentrations of acidic and basic sites of $\mathrm{MgO}$ were determined using solutions $(0.01 \mathrm{M})$ of triethylamine or benzoic acid in anhydrous toluene according to the procedure described elsewhere [25]. The measurements were performed at ambient temperature under dry nitrogen after $24 \mathrm{~h}$ contact of $\mathrm{MgO}$ with these solutions in grease-less glass reactors.

Acrolein (90\%, Aldrich) was dried over anhydrous $\mathrm{MgSO}_{4}$ at $273 \mathrm{~K}$ and distilled under normal pressure in nitrogen. The fraction that boils at 325-326 K was collected. This procedure was repeated with the obtained fraction. The distillate (b.p. 325.5-326.0 K) was collected in a Schlenk-type container and kept at $243 \mathrm{~K}$ in a freezer. Purity 99.4\% (GC). Commercial alcohols: methanol (p.a), ethanol (p.a, anhydrous 99.8\%), propan-2-ol (p.a.) and butan-1-ol (p.a.) all from POCh Gliwice Poland, as well as heptan-2-ol (98\%) and octan-2-ol (97\%), both from Aldrich, were used as hydrogen donors. All alcohols were distilled over metallic sodium and kept dry in Schlenk-type containers under nitrogen.

Catalytic activity measurements were carried out in a fixed-bed tubular glass reactor into which a sample of the catalyst $(0.250 \pm 0.005 \mathrm{~g})$ was loaded in a stream of dry nitrogen. A solution of acrolein in a hydrogen donor (at a given molar ratio) was dosed using a microdosing pump with a LHSV (Liquid Hourly Space Velocity): $3 \mathrm{~cm}^{3} \mathrm{~g}^{-1} \mathrm{~h}^{-1}$ into a stream of nitrogen $\left(50 \mathrm{~cm}^{3} \mathrm{~min}^{-1}\right)$ which was passed through the catalyst bed. The reaction products were collected in glass receivers, cooled to $213-223 \mathrm{~K}$ with a propan2-ol-dry ice mixture. Before activity measurements, the catalyst was maintained at $473 \mathrm{~K}$ in the stream of reactants for $60 \mathrm{~min}$. This procedure was omitted in the time-onstream experiment in which the activity of catalyst was measured directly after the introduction of substrates.

The reaction products were analyzed by GC (HRGC 4000B KONIK) equipped with a TRACER wax capillary column (length $30 \mathrm{~m}, 0.25 \mathrm{~mm}$ i.d.) and a flame ionization detector. $t$-Butylbenzene was used as an internal standard. The compounds were identified by GC-MS (HP-6890N with a $5973 \mathrm{~N}$ mass detector) and by comparison of the retention time with that of a standard sample. 
Thermodynamic calculations. All calculations leading to the evaluation of the Gibbs function $(\Delta G)$, the equilibrium constant $(\mathrm{K})$ and the thermodynamic yield $(\alpha)$ of the corresponding products at $673 \mathrm{~K}$ were based on data (enthalpies, entropies and molar heat capacities) taken from the National Institute of Standards and Technology (NIST) Standard Reference Database [26]. The list of equations that have been used to calculate thermodynamic data for all reactants participating in the studied reactions are given below:

$$
\begin{aligned}
& \Delta G(T)=\Delta H(T)-T \Delta S(T) \\
& \Delta H(T)=\Delta H_{298}^{0}+\int_{298}^{T} \Delta C_{p}(T) \mathrm{d} T \\
& \Delta S(T)= \Delta S_{298}^{0}+\int_{298}^{T} \frac{\Delta C_{p}(T)}{T} \mathrm{~d} T \\
& \Delta C_{p}(T)=a+b T+c T^{2}+\mathrm{d} T^{3} \\
& \Delta G(T)= \Delta H_{298}^{0}+\int_{298}^{T} \Delta C_{p}(T) \mathrm{d} T-T \Delta S_{298}^{0}+ \\
&-T \int_{298}^{T} \frac{\Delta C_{p}}{T}(T) \mathrm{d} T \\
& K=\exp \left(-\frac{\Delta G(T)}{R T}\right)
\end{aligned}
$$

\section{Results and Discussion}

\subsection{Characterization of $\mathrm{Mg}(\mathrm{OH})_{2}$ and $\mathrm{MgO}$}

Structural examination by powder X-ray diffraction showed that $\mathrm{Mg}(\mathrm{OH})_{2}$ dried at $473 \mathrm{~K}$ comprises the brucite phase only (Fig. 1a). $S_{\text {BET }}=27 \mathrm{~m}^{2} \mathrm{~g}^{-1}$, pore volume $V_{\mathrm{p}}=0.200 \mathrm{~cm}^{3} \mathrm{~g}^{-1}$ and average pore diameter $24 \mathrm{~nm}$. The TG-DTA analysis revealed that $T_{\max }$ for the decomposition of $\mathrm{Mg}(\mathrm{OH})_{2}$ is $692.9 \mathrm{~K}$ (Fig. 2) and weight loss (320-870 K) 30.41\% (exp), 30.89\% (calc).

Samples of $\mathrm{MgO}$ prepared by calcination of $\mathrm{Mg}(\mathrm{OH})_{2}$ at $873 \mathrm{~K}$ comprise of the periclase phase only (Fig. 1b). $\mathrm{S}_{\mathrm{BET}}=100 \mathrm{~m}^{2} \mathrm{~g}^{-1}, V_{\mathrm{p}}=0.529 \mathrm{~cm}^{3} \mathrm{~g}^{-1}$ and average pore diameter $17 \mathrm{~nm}$. Acid-base strength (H.) $7.2 \leq \mathrm{H}_{-}<33.0$; concentration of acidic sites $10 \mu \mathrm{mol} \mathrm{g}{ }^{-1}$, concentration of basic sites $1785 \mu \mathrm{mol} \mathrm{g}^{-1}$.

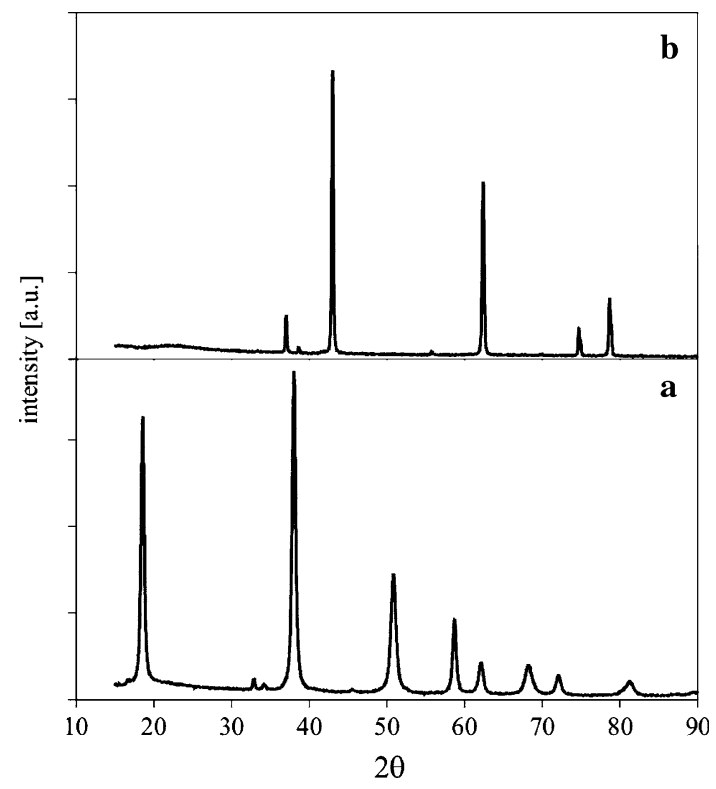

Fig. 1 X-ray diffraction patterns of $\mathrm{Mg}(\mathrm{OH})_{2}$ (a) and $\mathrm{MgO}$ (b)

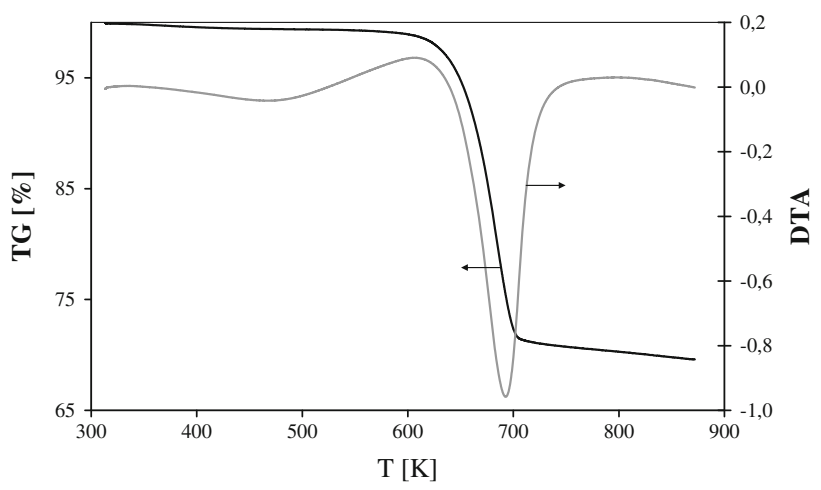

Fig. 2 TG-DTA analysis of $\mathrm{Mg}(\mathrm{OH})_{2}$

\subsection{Catalytic Activity Measurements}

The reactivity of six aliphatic alcohols, either primary or secondary, as hydrogen donors to acrolein has been studied in the presence of $\mathrm{MgO}$ as the catalyst (Table 1). Only straight-chained alcohols have been used in order to reduce the influence of steric effects on their reactivity. The reaction occurs according to the following scheme:

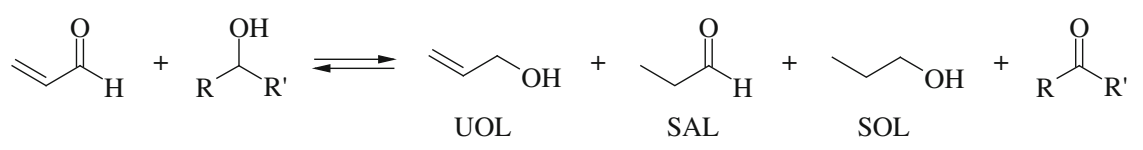


Table 1 Transfer hydrogenation of acrolein with studied alcohols over $\mathrm{MgO}$ as the catalyst

\begin{tabular}{|c|c|c|c|c|c|c|}
\hline \multirow[t]{2}{*}{ Donor } & \multirow[t]{2}{*}{$T(\mathrm{~K})$} & \multirow{2}{*}{$\begin{array}{l}\text { Conv. } \\
(\%)\end{array}$} & \multicolumn{4}{|c|}{ Moles from $100 \mathrm{~mol}$ of acrolein $^{\mathrm{a}}$} \\
\hline & & & UOL & SAL & SOL & Others \\
\hline \multirow[t]{3}{*}{$\mathrm{MeOH}$} & 573 & 3 & 3 & 0 & 0 & 0 \\
\hline & 623 & 8 & 7 & 1 & 0 & 0 \\
\hline & 673 & 13 & 8 & 3 & 1 & 1 \\
\hline \multirow[t]{3}{*}{$\mathrm{EtOH}$} & 573 & 22 & 20 & 1 & 0 & 1 \\
\hline & 623 & 43 & 38 & 3 & 1 & 1 \\
\hline & 673 & 64 & 50 & 7 & 4 & 3 \\
\hline \multirow[t]{3}{*}{ 1-BuOH } & 573 & 36 & 32 & 2 & 0 & 1 \\
\hline & 623 & 49 & 42 & 4 & 2 & 2 \\
\hline & 673 & 72 & 49 & 11 & 8 & 4 \\
\hline \multirow[t]{3}{*}{ 2-PrOH } & 573 & 10 & 9 & 1 & 0 & 0 \\
\hline & 623 & 19 & 16 & 1 & 1 & 1 \\
\hline & 673 & 31 & 22 & 4 & 3 & 2 \\
\hline \multirow[t]{3}{*}{ 2-HepOH } & 573 & 20 & 18 & 0 & 0 & 2 \\
\hline & 623 & 30 & 24 & 1 & 1 & 4 \\
\hline & 673 & 63 & $41^{\mathrm{b}}$ & 5 & 9 & 8 \\
\hline \multirow[t]{3}{*}{ 2-OctOH } & 573 & 19 & 18 & 1 & 0 & 0 \\
\hline & 623 & 32 & 26 & 2 & 1 & 3 \\
\hline & 673 & 65 & $40^{\mathrm{c}}$ & 7 & 12 & 6 \\
\hline
\end{tabular}

$D / A=3(\mathrm{~mol} / \mathrm{mol})$

${ }^{\text {a }} U O L$ allyl alcohol, $S A L$ propionaldehyde and $S O L$ propan-1-ol

b $8 \%$ of UOL was observed at $723 \mathrm{~K}$

c $3 \%$ of UOL was observed at $723 \mathrm{~K}$

where: $\mathrm{R}=\mathrm{H}, \mathrm{Me}, n-\mathrm{Pr}, n-\mathrm{Am}$ or $n$-Hex; $\mathrm{R}^{\prime}=\mathrm{H}$ or Me.

The CTH of acrolein with alcohols results in the formation of allyl alcohol (UOL), propionaldehyde (SAL), and propan-1-ol (SOL) as the reaction products. For all hydrogen donors allyl alcohol was the main reaction product. At $623 \mathrm{~K}$ the chemoselectivity of its formation higher than $80 \%$ ( $81-88 \%$ ) has been noted. For all donors the highest yields of allyl alcohol were achieved at $673 \mathrm{~K}$, although the reaction chemoselectivity was lowered to $62-78 \%$ only.

In general it has been stated that the reactivity of acrolein as the hydrogen acceptor from alcohols in the presence of $\mathrm{MgO}$ is very low compared to the reactivities determined for saturated carbonyl compounds [17, 18, 23, 2729]. At $473 \mathrm{~K}$ the conversion of acrolein (results not shown) did not exceed $10 \%$, whereas for saturated carbonyl compounds the conversions higher than $60 \%$ have been reported [17, 18, 23, 27, 29]. However, pronounced differences in the reactivities of alcohols as hydrogen donors in the transfer hydrogenation of acrolein have been observed. The results of studies performed within this work indicate that:
- ethanol and butan-1-ol are the most reactive hydrogen donors; 43 and $49 \%$ conversions of acrolein have already been obtained at $623 \mathrm{~K}$, respectively. For the former donor higher conversions $(\sim 65 \%)$ have been even noted [22];

- propan-2-ol is only a moderate hydrogen donor, whereas other secondary alcohols $\left(\mathrm{C}_{7}, \mathrm{C}_{8}\right)$ are much more reactive;

- at $673 \mathrm{~K}$ the reactivity of butan-1-ol exceeded the reactivities shown by ethanol and heavy secondary alcohols $\left(\mathrm{C}_{7}, \mathrm{C}_{8}\right)$, yet the chemoselectivities towards allyl alcohol were higher for both primary alcohols;

- methanol is the least reactive hydrogen donor.

Due to the fact that in the presence of ethanol or butan1-ol equally high yields of allyl alcohol in the chemoselective transfer hydrogenation of acrolein have been observed (49-50\%), further studies have been undertaken to explore optimum reaction conditions (Table 2) and the durability of the catalyst with a chosen donor (Fig. 3).

It has been shown that an increase in the donor-acceptor molar ratio to a value 6 resulted in an increase in the conversion of acrolein up to 86 and $89 \%$ at $673 \mathrm{~K}$ for ethanol and butan-1-ol, respectively. When $D / A=9$, slightly higher conversions of acrolein (89-91\%) for both alcohols have been noted only at $673 \mathrm{~K}$. For $D / A$ equal to 6 and 9, a decrease of the temperature of the maximum yield of allyl alcohol from 673 to $623 \mathrm{~K}$ for both alcohols as hydrogen donors has been observed. This maximum reached the value of $63-64 \%(D / A=6)$ at chemoselectivities 88 and $81 \%$ for

Table 2 Transfer hydrogenation of acrolein with ethanol or butan-1ol over $\mathrm{MgO}$ as the catalyst

\begin{tabular}{llllrrl}
\hline Donor & $T(\mathrm{~K})$ & Conv. (\%) & \multicolumn{4}{l}{ Moles from $100 \mathrm{~mol}$ of acrolein } \\
\cline { 4 - 7 } & & & UOL & SAL & SOL & Others \\
\hline EtOH & 573 & 51 & 47 & 2 & 1 & 1 \\
& 623 & 73 & 64 & 4 & 3 & 2 \\
& 673 & 86 & 59 & 8 & 16 & 3 \\
b & 573 & 52 & 44 & 4 & 3 & 1 \\
& 623 & 70 & 52 & 6 & 9 & 3 \\
& 673 & 89 & 49 & 9 & 27 & 4 \\
1-BuOH & 573 & 62 & 55 & 3 & 2 & 2 \\
& 623 & 78 & 63 & 4 & 7 & 4 \\
& 673 & 89 & 51 & 10 & 23 & 5 \\
b & 573 & 59 & 46 & 5 & 5 & 3 \\
& 623 & 72 & 49 & 7 & 13 & 4 \\
& 673 & 91 & 43 & 11 & 32 & 5 \\
\hline
\end{tabular}

$D / A=6$ and $9(\mathrm{~mol} / \mathrm{mol})$

a $U O L$ allyl alcohol, $S A L$ propionaldehyde and $S O L$ propan-1-ol

${ }^{\text {b }} D / A=9$ 


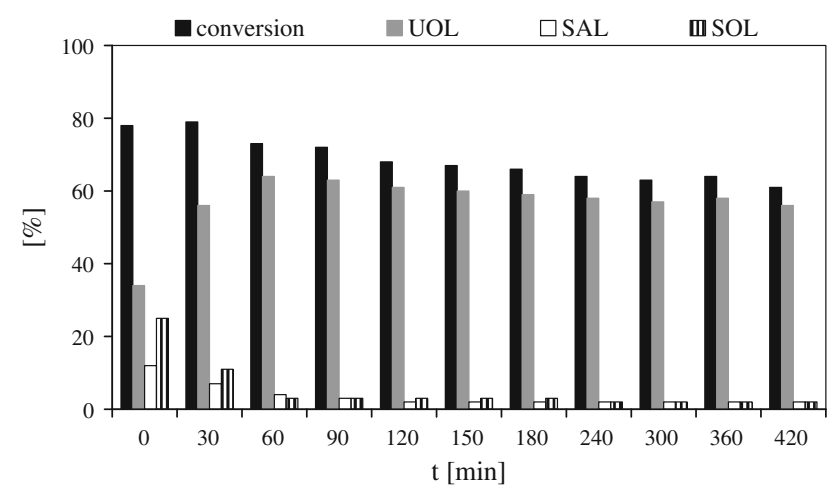

Fig. 3 Activity of $\mathrm{MgO}$ versus time (time-on-stream) in the reduction of acrolein with ethanol. $D / A=6(\mathrm{~mol} / \mathrm{mol}) . T=623 \mathrm{~K}$

ethanol and butan-1-ol, respectively. Only a slightly lower yield of allyl alcohol $(55 \%)$ has been reported in the first publication on CTH of acrolein [20]. A much higher yield of allyl alcohol $(73 \%)$ has been attained, however the catalyst was $\mathrm{MgO}-\mathrm{B}_{2} \mathrm{O}_{3}$ with propan-2-ol as the hydrogen donor [15]. At $D / A=9$, significant yields of propan-1-ol up to $27-32 \%$ have been attained, at the expense of allyl alcohol, lowering the yield of the latter (49-52\%). Ethanol was the most chemoselective hydrogen donor in the whole range of temperature (573-673 K). Hence, this alcohol has been chosen for the time-on-stream measurement.

At the beginning of the time-on-stream test $(0-30 \mathrm{~min})$ high conversions of acrolein (78-79\%) were accompanied by relatively low chemoselectivities (44-71\%) of its hydrogenation into allyl alcohol. The main side product was propan-1-ol, its yield reached $25 \%$ and decreased sharply with time.

It has also been found that in the first $30 \mathrm{~min}$ of the test noticeable amounts of crotonaldehyde were formed. This compound is a product of the aldol condensation reaction of acetaldehyde which occurs on the basic sites of magnesia, according to Eq. 6 presented in Sect. 3.3. Its yield decreased sharply with time reaching $11 \%, 5 \%$ and $1 \%$ after 0,30 , and $60 \mathrm{~min}$, respectively.

The yield of allyl alcohol increased steeply in the first period of the test (0-60 $\mathrm{min})$ from 34 to $64 \%$ mainly at the expense of propan-1-ol. The catalyst reached stable activity after $60 \mathrm{~min}$ in the stream of reactants. After that the chemoselectivity towards allyl alcohol reached $90 \%$, whereas the yield of alcohol was in the range of $60-56 \%$.

\subsection{Thermodynamic Description of the Process}

In order to elucidate the reasons of such big differences in the reactivities of alcohols, as well as the low reactivity of acrolein, a thermodynamic analysis of the dehydrogenation of alcohols and the transfer hydrogenation reactions of acrolein has been performed. The calculations have been done for $673 \mathrm{~K}$ since this was the temperature at which the maximum yield of allyl alcohol had been observed (Tables 3, 4, 5, 6). For the purpose of analysis, the description of a course of the following reactions has been assumed:
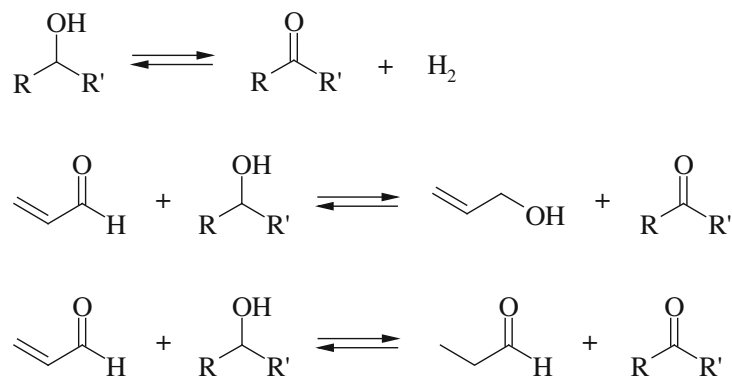

$\stackrel{\mathrm{O}}{\mathrm{H}}+2{ }_{\mathrm{R}}{\stackrel{\mathrm{OH}}{\mathrm{R}^{\prime}}} \rightleftharpoons \sim_{\mathrm{OH}}+2{ }_{\mathrm{R}^{\prime}}{\stackrel{\mathrm{O}}{\mathrm{R}^{\prime}}}$

where: $\mathrm{R}=\mathrm{H}, \mathrm{Me}, n$-Pr, $n$-Am, $n$-Hex and $\mathrm{R}^{\prime}=\mathrm{H}$, Me.

The thermodynamic analysis of the dehydrogenation of alcohols and the transfer hydrogenation reactions of acrolein can be summarized as follows:

- for all alcohols except methanol the dehydrogenation at $673 \mathrm{~K}$ is thermodynamically favorable $(\Delta G<0)$;

- secondary alcohols are more prone to release hydrogen than the primary ones;

- butan-1-ol is slightly more susceptible to dehydrogenation than ethanol;

- the CTH of acrolein into allyl alcohol is not thermodynamically favorable $(\Delta G>0)$, irrespective of the type of the alcohol used as the hydrogen donor;

- the formation of propionaldehyde is favored thermodynamically $(\Delta G<0)$, irrespective of the type of alcohol used as the hydrogen donor;

- allyl alcohol is unstable in comparison with propionaldehyde; the magnitude of the instability is expressed by a value of $51.65 \mathrm{~kJ} \mathrm{~mol}^{-1}$;

- the formation of propan-1-ol is thermodynamically favored $(\Delta G<0)$ for all alcohols as hydrogen donors except methanol;

Table 3 Calculated thermodynamic data for the dehydrogenation at $673 \mathrm{~K}$ of the studied alcohols

\begin{tabular}{lccc}
\hline Alcohol & $\Delta G\left(\mathrm{~kJ} \mathrm{~mol}^{-1}\right)$ & \multicolumn{1}{l}{$K$} & $\alpha(\%)$ \\
\hline $\mathrm{MeOH}$ & 8.25 & 0.2289 & 18.6 \\
EtOH & -8.35 & 4.4933 & 81.6 \\
1-BuOH & -11.26 & 7.4841 & 88.2 \\
2-PrOH & -20.09 & 36.2611 & 97.3 \\
2-HepOH & -21.96 & 50.6280 & 98.1 \\
2-OctOH & -20.95 & 42.3038 & 97.7 \\
\hline
\end{tabular}


Table 4 Calculated thermodynamic data for the transfer hydrogenation of acrolein by studied alcohols at $673 \mathrm{~K}$ with the formation of allyl alcohol

\begin{tabular}{lllc}
\hline Donor & $\Delta G\left(\mathrm{~kJ} \mathrm{~mol}^{-1}\right)$ & $K$ & $\alpha^{\mathrm{a}}(\%)$ \\
\hline $\mathrm{MeOH}$ & 34.62 & 0.0021 & 7.5 \\
EtOH & 18.02 & 0.0400 & $28.0^{\mathrm{b}}$ \\
1-BuOH & 15.11 & 0.0672 & $34.3^{\mathrm{c}}$ \\
2-PrOH & 6.28 & 0.3257 & 57.7 \\
2-HepOH & 4.41 & 0.4548 & 63.1 \\
2-OctOH & 5.41 & 0.3800 & 60.2 \\
\hline
\end{tabular}

a $D / A=3$

b $\alpha=37.5 \%$ for $D / A=6$

c $\alpha=45.2 \%$ for $D / A=6$

Table 5 Calculated thermodynamic data for the transfer hydrogenation of acrolein by studied alcohols at $673 \mathrm{~K}$ with the formation of propionaldehyde

\begin{tabular}{llcr}
\hline Donor & $\Delta G\left(\mathrm{~kJ} \mathrm{~mol}^{-1}\right)$ & $K$ & $\alpha^{\mathrm{a}}(\%)$ \\
\hline $\mathrm{MeOH}$ & -17.03 & 20.98 & 97.7 \\
$\mathrm{EtOH}$ & -33.63 & 407.8 & 99.9 \\
1- $\mathrm{BuOH}$ & -36.54 & 686.0 & $>99.9$ \\
2-PrOH & -45.37 & 3324 & $>99.9$ \\
2- $\mathrm{HepOH}$ & -47.24 & 4640 & $>99.9$ \\
2-OctOH & -46.24 & 3878 & $>99.9$ \\
\hline
\end{tabular}

${ }^{\text {a }} D / A=3$

Table 6 Calculated thermodynamic data for the transfer hydrogenation of acrolein by studied alcohols at $673 \mathrm{~K}$ with the formation of propan-1-ol

\begin{tabular}{lccc}
\hline Donor & $\Delta G\left(\mathrm{~kJ} \mathrm{~mol}^{-1}\right)$ & $K$ & $\alpha^{\mathrm{a}}(\%)$ \\
\hline $\mathrm{MeOH}$ & 1.48 & 0.7678 & 61.5 \\
EtOH & -31.73 & 290.2 & 98.7 \\
1-BuOH & -37.55 & 821.1 & 99.5 \\
2-PrOH & -55.21 & 19275 & 99.9 \\
2-HepOH & -58.94 & 37575 & 99.9 \\
2-OctOH & -56.93 & 26235 & 99.9 \\
\hline
\end{tabular}

${ }^{a} D / A=3$

- propan-1-ol is the most stable product of the transfer hydrogenation of acrolein for butan-1-ol and all secondary alcohols as hydrogen donors;

- propan-1-ol is unstable in comparison with propionaldehyde only for ethanol as the hydrogen donor, the magnitude of the instability is expressed by a value of $1.9 \mathrm{~kJ} \mathrm{~mol}^{-1}$.

Therefore, it can be concluded that the CTH of acrolein into allyl alcohol with alcohols as hydrogen donors must be kinetically controlled due to the instability of the main product in comparison to the others. Moreover, upon comparing the experimental values of the yield of allyl alcohol with those calculated in the thermodynamic analysis of the process it has been found that the used hydrogen donors, except ethanol and butan-1-ol, follow the thermodynamic model of CTH of acrolein described by Eq. 3. In the case of the above-mentioned exceptions, the experimentally determined yields of allyl alcohol greatly exceeded the thermodynamic yields for both donor-acceptor molar ratios (Table 7). The results obtained in the past for ethanol as hydrogen donor [20, 22] also exceeded those predicted by thermodynamic calculation based on Eq. 3 . Such a significant difference in yields is not within experimental error. The origin of this discrepancy must be the occurrence of a disregarded reaction for which $\Delta G<0$, which influences the $\mathrm{CTH}$ reaction. After careful inspection of the possible reactions the aldol condensation of acetaldehyde or butyraldehyde, the products of the transfer hydrogenation reaction between ethanol or butan-1-ol and acrolein has been chosen (Eqs. 6-7):<smiles>CCCC=CC(C)CCCC</smiles>

The aldol condensation of both aldehydes is strongly favored thermodynamically, e.g. for acetaldehyde $\Delta G(673 \mathrm{~K})=-20.34 \mathrm{~kJ} \mathrm{~mol}^{-1}$. However, its products are present only at the beginning of the $\mathrm{CTH}$ of acrolein with ethanol or butan-1-ol. Therefore, the participation of this reaction in the preliminary period of the test has no influence on the yield of allyl alcohol observed after $60 \mathrm{~min}$ of the reaction. Hence, the aldol condensation of the above-mentioned aldehydes cannot be considered the reason of such a significant difference in yields of allyl

Table 7 Theoretical and experimental yields of allyl alcohol obtained in the transfer hydrogenation of acrolein by ethanol or butan1 -ol at $673 \mathrm{~K}$

\begin{tabular}{|c|c|c|c|c|}
\hline \multirow[t]{2}{*}{ Donor } & \multicolumn{2}{|c|}{$D / A=3, \alpha(\%)$} & \multicolumn{2}{|c|}{$D / A=6, \alpha(\%)$} \\
\hline & calc & $\exp$ & calc & $\exp$ \\
\hline \multirow[t]{2}{*}{$\mathrm{EtOH}$} & 28.0 & $47^{\mathrm{a}}$ & 37.5 & $55^{\mathrm{b}}$ \\
\hline & & $50^{\mathrm{c}}$ & & $64^{\mathrm{cd}}$ \\
\hline \multirow[t]{2}{*}{$1-\mathrm{BuOH}$} & 34.3 & $49^{c}$ & 45.2 & $33^{\mathrm{b}}$ \\
\hline & & & & $63^{\mathrm{cd}}$ \\
\hline
\end{tabular}

\footnotetext{
${ }^{a}$ At $653 \mathrm{~K}$ [22]

b $[20]$

c This work

d At $623 \mathrm{~K}$
} 
alcohol as the one observed by us, as well as by others [20, 22]. Therefore, the explanation of this discrepancy is still an open question.

\section{Conclusions}

The main achievements of our work are showing that:

- the CTH of acrolein by various alcohols in the presence of $\mathrm{MgO}$ as the catalyst leads to the formation of allyl alcohol with a high chemoselectivity $(>80 \%)$. For ethanol or butan-1-ol as hydrogen donors at $D / A=6$ the maximum yield of allyl alcohol reaches $63-64 \%$;

- ethanol and butan-1-ol are the most reactive hydrogen donors among the studied primary and secondary alcohols, although in the light of the results of thermodynamic calculations the secondary alcohols should be more reactive;

- the CTH reaction of acrolein in the presence of $\mathrm{MgO}$ is a process which is kinetically controlled since allyl alcohol is unstable in comparison to other products: propionaldehyde and propan-1-ol;

- the thermodynamic analysis of the $\mathrm{CTH}$ reaction expressed by the following equation:

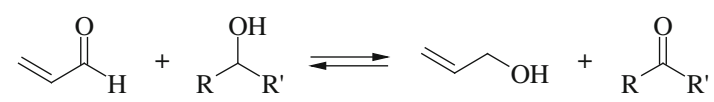

reveals that the reactivity of alcohols used as hydrogen donors, except ethanol and butan-1-ol, follow the thermodynamic model of CTH of acrolein described by Eq. 3 . These exceptions can be explained by the occurrence of an unaccounted for reaction for which $\Delta G<0$. It has also been shown by us that the aldol condensation of acetaldehyde or butyraldehyde over $\mathrm{MgO}$ cannot be considered as the reason for the occurrence of such a significant difference in experimental and calculated yields of allyl alcohol.

Acknowledgment The authors wish to express their thanks to the Polish State Committee for Scientific Research for supporting this work (Grant No. 1 T09B 108 30).

Open Access This article is distributed under the terms of the Creative Commons Attribution Noncommercial License which permits any noncommercial use, distribution, and reproduction in any medium, provided the original author(s) and source are credited.

\section{References}

1. Keinan E, Greenspoon N (1991) In: Trost BM and Fleming I (eds) Comprehensive organic synthesis, vol. 8 chap 3.5. Pergamon Press, Oxford

2. Hudlický M (1996) Reductions in organic chemistry. ACS, Washington, D.C

3. Mäki-Arvela P, Hájek J, Salmi T, DYu Murzin (2005) Appl Catal A 292:1

4. Barrero AF, Alvarez-Manzaneda EJ, Chahboun R, Meneses R (1999) Synlett 1663

5. Alonso F, Osante I, Yus M (2006) Synlett 3017

6. Zanella R, Louis C, Giorgio S, Touroude R (2004) J Catal 223:328

7. Milone C, Ingoglia R, Schipilliti L, Crisafulli C, Neri G, Galvagno S (2005) J Catal 236:80

8. Johnstone RA, Wilby AH, Entwistle ID (1985) Chem Rev 85:129

9. Kellogg RM (1991) In: Trost BM and Fleming I (eds) Comprehensive organic synthesis, vol 8, chaps 1,3. Pergamon Press, Oxford

10. Bäckvall J-E (2002) J Organometal Chem 652:105

11. Di Cosimo JI, Acosta A, Apesteguía CR (2005) J Mol Catal A 234:111

12. Aramendía MA, Borau V, Jiménez C, Marinas JM, Ruiz JR, Urbano F (2001) J Mol Catal A 171:153

13. Braun F, Di Cosimo JI (2006) Catal Today 116:206

14. Aramendía MA, Borau V, Jiménez C, Marinas JM, Ruiz JR, Urbano F (2001) Appl Catal A 206:95

15. Ueshima M, Shimasaki Y (1992) Chem Lett 21:1345

16. Aramendía MA, Borau V, Jiménez C, Marinas JM, Ruiz JR, Urbano F (1998) Appl Catal A 172:31

17. Ruiz JR, Sanchidrian CJ (2007) Curr Org Chem 11:1113

18. Chuah GK, Jaenicke S, Zhu YZ, Liu SH (2006) Curr Org Chem 10:1639

19. Grünert W, Brückner A, Hofmeister H, Claus P (2004) J Phys Chem B 108:5709

20. Ballard SA, Finch HD, Winkler DE (1957) Adv Catal 9:754

21. Gliński M, Ulkowska U, Gibka J (2008) Proceedings of 9th Pannonian international symposium on catalysis, Strbske Pleso, Slovakia 234, ISBN 978-80-227-2923-9

22. Kobyliński T, Malinowski S, Zatorski W (1968) Rocz Chem 42:1899. CA: 70:105586u

23. Gliński M (2008) Appl Catal A 349:133

24. Tanabe K, Misono M, Ono Y, Hattori H (1989) Stud Surf Sci Catal 51:5

25. Yamanaka T, Tanabe K (1975) J Phys Chem 79:2409

26. Stein SE, Brown RL (2009) Structures and properties group additivity model. In: Linstrom PJ, Mallard WG (eds) NIST chemistry WebBook, NIST Standard Reference Database Number 69. National Institute of Standards and Technology, Gaithersburg MD, 20899, http://webbook.nist.gov, retrieved Dec 17, 2009

27. Gliński M (2010) React Kinet Mech Catal 99:93

28. Gliński M (2009) React Kinet Catal Lett 97:275

29. Gliński M (2009) Polish J Chem 83:187 